Jpn. J. Med. Mycol.

Vol.32, Suppl. 109-119, 1991

ISSN 0916-4804

\title{
A Recent Trend in Chemotherapy for Deep-Seated Mycosis
}

\author{
Akira ITO \\ Division of Clinical Laboratory*, \\ Yokohama City University School of Medicine, \\ 3-9, Fukuura, Kanazawa-ku, Yokohama 236, Japan
}

Increasingly high incidence of deep-seated mycosis in immunocompromised patients with underlying diseases such as hematopoietic malignancies, solid tumors, organ transplants and AIDS has presented serious problems in recent years in Japan due to difficulties in treatment and high mortality.

At present, only 4 antifungal agents are available to treat these disease in Japan; amphotericin B, flucytosine, miconazole and fluconazole.

But the treatment of deep-seated mycosis is limited due to difficulties of early diagnosis and side effects by amphotericin B.

The antifungal agents and recent advance in chemotherapy for deep-seated mycosis are reviewed from the literature on the following points; antifungal agents at present and in future, improvement and dosage form modification of existing antifungal agents, new attempts for reducing adverse events and new informations about the adverse events and the interactions of antifungal agents. Besides antifungal agents, adjuvant therapies with immunomodifiers (BRM) and cytokines play an important role in the treatment of mycosis, but I narrowed down the focus to only antifungal agents in this paper.

Key words: deep-seated mycosis, antifungal agent, drug interaction, adverse reactions, co-administration

\section{Introduction}

Increasingly high incidence of deep-seated mycosis in immunocompromised patients with underlying diseases such as hematopoietic malignancies, solid tumors, organ transplants and AIDS has presented serious problems in recent years in Japan due to difficulties in treatment and high mortality.

The antifungal agents and recent advance in chemotherapy for deep-seated mycosis are

*The former position: The first Department of Internal Medicine reviewed from the literature with reference to recent progress in treatment and key points which must be taken into account in their clinical use.

1. Antifungal agents at present and in future At present, only 4 antifungal agents are available to treat deep-seated mycosis in Japan: amphotericin B, flucytosine, miconazole and fluconazole. Ketoconazole has not yet been commercially available, although it has been approved by the MHW. In addition to these 5 drugs, a number of new compounds are under development for the treatment of deep-seated mycosis, with some of them being 
in the clinical stage.

In addition to inhibitors of ergosterol synthesis, mainly azole derivatives, various antibiotics with new chemical structures and mechanisms of action will be studied as antifungal agent for the treatment of deepseated mycosis (Table 1).

Antibiotics which inhibit the cell wall synthesis include nikkomycin $\mathrm{Z}^{1-3}$ ) which inhibits the synthesis of chitin and cilofungin (LY-12019) which inhibits the synthesis of beta-glucan. Nikkomycin Z, a compound developed in Germany, has a chemical structure similar to that of polyoxin which has been used as an agricultural chemical in Japan. Although it has been found to be effective for Coccidioides immitis and Blastomyces dermatitidis, it shows no antifungal activity against other fungi of ten encountered in Japan. Cilofungin ${ }^{1-3)}$, a semisynthetic derivative of echinocandin $B$, was developed by E. Lilly in the US and has been found to show potent activity against only
Candida albicans and Candida tropicalis in animal experiments and can be administered intravenously. It looks like a promising agent.

RI-331 1,3) which is being co-developed by Taisho Pharmaceutical Co., Ltd. and Teikyo University is an antifungal agent with new mechanisms of action which can be administered both orally and intravenously. It affects a route of the synthesis of aspartic acid group amino acid which is present in fungi but not in humans. It has therefore very selective toxicity and high safety margin in humans. However, it has no activity against Aspergillus spp.

Other recently highlighted new compounds include benanomycin $A^{1,3,4)}$, a water-soluble and low toxic, belonging to benzonaphthacequinon antibiotic discovered by the Institute of Microbial Chemistry, Meiji Seika and Teikyo University which shows potent in vivo antifungal activity comparable to that of amphotericin B though yet unknown

Table 1. Antifungal agents for systemic fungal infections

Including those under development

1. Inhibitors of high molecular substance in the cell walls

echinocandin $\longrightarrow$ cilofungin (LY-12019)

nikkomycin Z

2. Ergosterol biosynthesis inhibitors : EBI

polyene amphotericin $\mathrm{B}$ *

azole

imidazole miconazole*

triazole fluconazole*

itraconazole

SM8668 (Sch 39304) SM9164 (Sch 42427)

saperconazole (R66905)

3. Amino acid biosynthesis inhibitors

RI-331

4. Mechanism unknown

benanomicin A

pradimicin A (BMY-28864)

5. DNA biosynthesis inhibitors

flucytosine*

*already launched in Japan 
<smiles>Cn1ncn1CC(O)(CN1CC2CC1C2)c1ccc(F)cc1F</smiles>

fluconazole<smiles>COS(=O)(=O)C(C)C(O)(Cn1cncn1)c1ccc(F)cc1F</smiles>

SM 8668(Sch 39304)

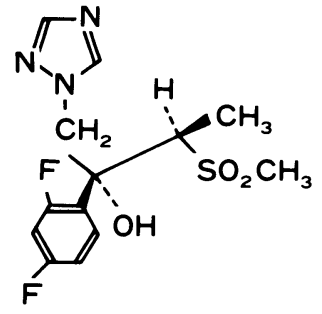

SM-9164(Sch 42427)

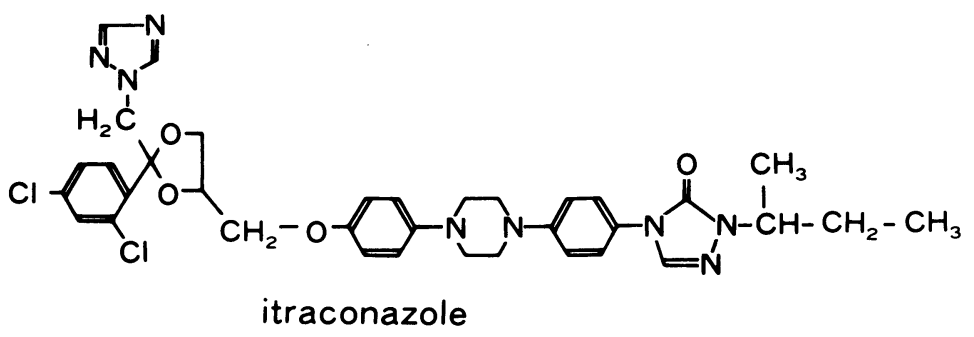<smiles>CCOc1ccc(N2CCN(c3ccc(-n4cnn(C(C)CC)c4=O)cc3)CC2)cc1</smiles>

Fig. 1. Triazole antifungals already launched and currently in development

mechanisms of action, and pradimicin $\mathrm{A}^{1,3)}$ (BMY-28864) synthesized by Bristol-Myers Research Institute.

New inhibitors of ergosterol synthesis which are under development include new azole antifungals ${ }^{1-3,5-9)}$ in particular triazole antifungals. Fig. 1 shows the chemical formula of triazole derivatives which are currently used or which seem promising for the treatment of deep-seated mycosis.

Itraconazole ${ }^{1-3,5-9)}$ is an oral antifungal agent developed by Janssen. It has been found to show potent antifungal activity against not only Candida spp. and Cryptococcus neoformans but also Aspergillus spp.
In clinical studies of long-term administration with itraconazole conducted in various countries, it was orally administered at 100 $400 \mathrm{mg} /$ day for 1 to several months or even for more than 1 year in some cases for the treatment of candidiasis, cryptococcal meningitis and aspergillosis of various types $10-14)$. An improvement rate of $57 \%$ was obtained in pulmonary aspergilloma, while 74 $\%$ to $90 \%$ improvement rates were reported in aspergillosis of other types (Table 2).

Itraconazole is already on the market in 10 countries, including Mexico, the UK and Belgium. In Japan, study groups organized in the fields of internal medicine and dermatology 
Table 2. Overall results with long-term itraconazole therapy

\begin{tabular}{|c|c|c|c|c|c|c|c|c|}
\hline & $\begin{array}{l}\text { No. of } \\
\text { patients }\end{array}$ & $\begin{array}{l}\text { cured and } \\
\text { marked } \\
\text { improvement } \\
\quad(\%)\end{array}$ & $\begin{array}{l}\text { moderate } \\
\text { improvement } \\
\quad(\%)\end{array}$ & $\begin{array}{c}\text { no change } \\
(\%)\end{array}$ & $\begin{array}{c}\text { deterioration } \\
(\%)\end{array}$ & $\begin{array}{l}\text { median } \\
\text { dosage } \\
(\mathrm{mg})\end{array}$ & $\begin{array}{l}\text { median } \\
\text { therapy } \\
\text { length }\end{array}$ & reference \\
\hline Candidosis & 55 & 69 & 11 & 15 & 5 & 200 & 1 month & 10 \\
\hline $\begin{array}{l}\text { Cryptococcus } \\
\text { meningitis }\end{array}$ & 20 & 65 & 25 & & & 400 & 4.8 months & 11 \\
\hline $\begin{array}{l}\text { invasive } \\
\text { aspergillosis }\end{array}$ & 35 & 60 & 14 & 6 & 20 & $100-400$ & $11-372$ days & 12 \\
\hline $\begin{array}{l}\text { invasive } \\
\text { aspergillosis }\end{array}$ & 15 & & & 13 & 7 & $100-400$ & $0.5-12$ months & 13 \\
\hline $\begin{array}{l}\text { chronic } \\
\text { necrotising } \\
\text { pulmonary } \\
\text { aspergillosis }\end{array}$ & 44 & 66 & 23 & 7 & 5 & $100-400$ & 18-563 days & 12 \\
\hline $\begin{array}{l}\text { chronic } \\
\text { pulmonary } \\
\text { aspergilloma }\end{array}$ & 42 & 40 & 17 & 27 & 14 & $100-400$ & $18-780$ days & 12 \\
\hline
\end{tabular}

are conducting clinical studies in patients with deep-seated mycosis and cutaneous mycosis of various types. Data are being compiled and analyzed.

Among triazole antifungal agents, saperconazole ( R-66905) developed by Janssen has been found to show potent activity against Aspergillus spp. ${ }^{15,16)}$ and is expected to be useful for the treatment of aspergillosis ${ }^{17)}$.

SM8668 (SCH 39304) ${ }^{18-21)}$ is an oral agent developed by Sumitomo Pharmaceutical and Schering. Its active metabolite, SM9164 (SCH 42427) ${ }^{3)}$, can be administered both orally and intravenously and shows potent activity against Candida spp., Cryptococcus neoformans and Aspergillus spp. It has been recently brought into the spotlight because of its potent in vivo activities and high concentrations in the cerebrospinal fluid ${ }^{21)}$.

Fluconazole was launched onto the Japanese market about 1 year ago. Parenteral and oral dosage forms are available. It is indicated for the treatment of deep-seated mycosis. Parenteral dosage forms are available in about 10 countries, including the US, Italy and Switzerland. Major differences in the package inserts used in Japan and the US are that the initial dose of 200 to $400 \mathrm{mg}$ is recommended, followed by follow-up doses of 100 to $200 \mathrm{mg} /$ day on the $2 \mathrm{nd}$ and subsequent days of treatment for both candidiasis and cryptococcal meningitis and that the drug is not indicated for aspergillosis in the US ${ }^{22-}$ 25).

\section{Improvement and dosage form modification}

Recently, there have been some new developments regarding the improvement and dosage form modification of existing antifungal drugs.

Miconazole has been made available in the form of gel in more than 40 countries such as Belgium, the UK and France for the local treatment of oral candidiasis. It promptly cures lesions such as fur and redness upon direct application to affected areas. Reported adverse reactions include nausea and, in longterm treatment, diarrhea. In Japan, miconazole is available as vaginal suppositories, cream and lotion for topical use, and an injectable preparation, but gel is still under development. 
Flucytosine is administered only orally in Japan. Since tablets are too big due to large doses required, the development of a parenteral dosage form is needed. Major problems associated with the parenteral dosage form used in other countries include, however, that it must be stored at 18 to $25{ }^{\circ} \mathrm{C}$ and that $250 \mathrm{ml}$ must be infused 4 times a day, i.e., $1,000 \mathrm{ml} /$ day, as a $1 \%$ solution in 5 -FC ${ }^{26)}$. These may be the reasons why the parenteral dosage form has not yet been made available in Japan.

Amphotericin B exerts potent antifungal activities against various fungi both in vitro and clinically. However, it presents several problems related to pharmacokinetics and adverse reactions. In particular, the parenteral dosage form is difficult to use due to significant adverse reactions. Efforts were made to alleviate its adverse reactions by methylating the compound, but this attempt failed due to decreases in antifungal activities and onset of leukoencephalosis. At present, various preparations in which amphotericin $B$ is carried by various vehicles such as liposomes, lipid complexes and lipid microspheres using DDS (drug delivery system) technologies which have rapidly progressed in recent years are being developed 27-29). Amphotericin B included in liposome makes it possible to deliver the drug to inflammatory tissues at high concentrations when administered at high doses $(2-6 \mathrm{mg} / \mathrm{kg})$. In addition, adverse reactions of amphotericin $B$ can be reduced as a result of inclusion ${ }^{27)}$. Clinical studies are ongoing in the US and Europe using this preparation in patients who resist antifungal treatment, those with renal failure and those in whom amphotericin B and other drugs may cause renal dysfunction ${ }^{3)}$. Clinical studies are expected to be started in Japan in the near future.

\section{Some new attempts reducing adverse events by amphotericin B}

Various attempts are being made to alleviate adverse reactions of amphotericin $B$.

One of the treatment regimens used to avoid adverse reactions such as fever, chills and renal dysfunction consists of administering steroids by i.v. infusion before administration of amphotericin B and administering mannitol immediately before the completion of drip infusion of amphotericin B.

Sano and his colleagues ${ }^{30)}$ at Showa University have reported that when the drug (20-30 $\mathrm{mg} /$ day) was administered by continuous drip infusion at a rate of $1 \mathrm{ml} / \mathrm{hr}$ over $24 \mathrm{hrs}$ using an infusion pump for insulin, blood concentrations could be maintained at about $0.6 \mathrm{mg} / \mathrm{ml}$ with no adverse reactions and that this treatment regimen was useful for the treatment and prevention of mycosis in leukemia patients.

According to Takeshita and his colleagues ${ }^{31)}$ at Hamamatsu University, School of Medicine, the low dose infusion with the maximum daily dose of 8 to $10 \mathrm{mg}$ was less likely to cause adverse reactions than the usual dose of 30 to $50 \mathrm{mg}$ and was effective for the prevention of mycosis in acute leukemia patients.

When this treatment regimen was used, there were significant differences between patients who received amphotericin $\mathrm{B}$ and those who did not in terms of the feverish period (37.5 ${ }^{\circ} \mathrm{C}$ and over), fever-free period $\left(37^{\circ} \mathrm{C}\right.$ or less) and peak CRP values. The incidence of positive fungal cultures was also significantly different between the two groups, indicating that the treatment is clinically useful.

A syrup of amphotericin B has been found to be effective in preventing mycosis when orally administered upon onset of granulocytopenia during the treatment for leukemia.

Although this dosage form was not considered to be absorbed when administered orally, recent studies have shown that blood concentrations of about $0.2 \mu \mathrm{g} / \mathrm{ml}$ can be obtained $4 \mathrm{hrs}$ after oral administration of $2,400 \mathrm{mg} /$ day in 3 divided daily doses ${ }^{32)}$. This dosage form is therefore used upon onset of granulocytopenia during the treatment for leukemia. Improvement is needed, however, in various aspects, such as to improve the taste 
to facilitate ingestion and to increase the absorption rate to reduce the required dose.

Furthermore, the syrup of amphotericin B has been found to show therapeutic efficacy for deep-seated mycosis when orally administered at high doses ${ }^{33)}$. In the literature, the diagnosis of mycosis was established in 66 of 103 cases treated with $2,400 \mathrm{mg} /$ day and greater doses in Japan. The drug was clinically evaluated to be "markedly effective" or "effective" in 44 of these 66 cases $(66.7 \%)$. 26 of 40 fungal strains $(65.0 \%)$ detected were eradicated.

The incidence of adverse reactions was far lower than that seen with the parenteral version, with GI symptoms occurring in only about $1 \%$ of 103 cases. The incidence of abnormal laboratory tests such as elevation of BUN and creatinine and hypopotassemia was also about $1 \%{ }^{33)}$.

\section{New information of adverse reactions}

Table 3 shows the incidence of adverse reactions of antifungal agents mentioned in the reference ${ }^{34,35)}$ and in the package insert of each drug in Japan. The data for the parenteral dosage form of amphotericin B is that collected from the literature. As drugs are brought into common clinical use, the incidence of adverse reactions may change and reactions unknown at an earlier stage may occur.

For example, although the reported incidence of adverse reactions was $23.0 \%{ }^{34)}$ for miconazole at an early stage after launching, it decreased by almost $50 \%$ by November 4 , $1989^{3)}$. However, adverse reactions which were not reported at an early stage such as renal dysfunction and abnormal electrolyte levels were reported later.

The incidence of adverse reactions to triazole antifungal agents is generally considered to be relatively low. Serious adverse reactions are also rare. In fact, the incidence indicated in the US Formulary Review 23) is lower for fluconazole than for amphotericin B.

The incidence of abnormal laboratory tests are also far lower for fluconazole than for amphotericin B 23-25) and the incidence of abnormal hepatic function tests is comparable for the two drugs ${ }^{3)}$.

The following adverse reactions occurred in at least $1 \%$ of 4,048 cases treated with fluconazole for at least 7 days in the US $23-$ $25)$ : nausea $(3.7 \%)$, headache $(1.9 \%)$, skin eruption $(1.8 \%)$, abdominal pain $(1.7 \%)$, vomiting $(1.7 \%)$ and diarrhea $(1.5 \%)$. Major adverse reactions were gastrointestinal. It is reported that all adverse reactions were

Table 3. Incidence of adverse events in Japan

\begin{tabular}{c|c|c|c}
\hline \multicolumn{2}{c|}{ antifungal agents } & $\%$ & Reference \\
\hline \multirow{2}{*}{ AMPH } & oral & 6.2 & $* *$ \\
\cline { 2 - 4 } & intravenous & 54.4 & $*$ \\
\hline \multirow{2}{*}{$5 \mathrm{FC}$} & oral & 21.9 & $* *$ \\
\hline \multirow{2}{*}{$\mathrm{MCZ}$} & intravenous & 23.0 & 34 \\
\hline \multirow{2}{*}{ FCZ } & oral & 8.3 & 35 \\
\cline { 2 - 4 } & intravenous & 4.9 & 35 \\
\hline
\end{tabular}

* refer to literature in Japan collected and analized by author.

**refer to package insert 
mild and the treatment was required to be discontinued in only 61 cases $(1.5 \%)$ due to adverse reactions.

The incidence of adverse reactions to fluconazole reported in Japan ${ }^{35)}$ is $6.5 \%$ (13 $/ 199$ cases), $4.9 \%$ for the parenteral dosage form and $8.3 \%$ for the oral dosage form, although the number of monitor cases is still about 100 for each of the two dosage forms.

Overall, the incidence of abnormal laboratory tests was $17.6 \%$. All abnormalities were mild and transient and the overall incidence was comparable to that reported for oral amphotericin B in the US, although the incidence of elevation of GOT, GPT and gamma-GTP exceeded $10 \%$ for the parenteral dosage form.

In experience of our patients, 70 years old male with pulmonary tuberculosis associated with oral candidiasis, GOT increased from 32 to $380 \mathrm{IU} / \mathrm{ml}$ and GPT from 14 to $189 \mathrm{IU}$ $/ \mathrm{ml}$ when rifampicin and fluconazole were coadministered. Both GOT and GPT showed a tendency to decrease upon withdrawal of fluconazole and returned to normal upon discontinuation of rifampicin. Later on, no elevation was seen although rifampicin treatment was resumed.

Transient elevation of GOT and GPT was reported in 4 of the 22 AIDS patients associated with cryptococcus meningitis ${ }^{36)}$. The prescribing information of fluconazole used in the US states that 8 -fold or greater increases in transaminase levels are seen in about $1 \%$ of patients ${ }^{25)}$ and that transaminase levels are liable to increase when fluconazole is co-administered with hepatotoxic drugs, although a return to normal is generally seen upon discontinuation of treatment. Therefore, cautious administration is recommended.

\section{Interactions after co-administration of different antifungal agents}

A typical example of synergism produced by co-administration of different antifungal agents which was clinically established is that of amphotericin B and flucytosine in the treatment of cryptococcal meningitis ${ }^{37-40)}$.
In 28 cases of cryptococcal meningitis studied in Japan 38,39 ), co-administration of amphotericin B and flucytosine compared favorably to either drug alone in terms of therapeutic efficacy, fungi eradication rate and incidence of side effects.

Co-administration of amphotericin B and flucytosine, followed by flucytosine alone was more effective than amphotericin $B$ alone or flucytosine alone, followed by coadministration.

Some authors ${ }^{41-43)}$ report that amphotericin B (AMPH) should not be co-administered with miconazole (MCZ) because the latter prevents AMPH from coming bound to the cell membrane by inhibiting the synthesis of ergosterol, resulting in the reduction in the efficacy of AMPH, while others 44) found that MCZ did not antagonize AMPH or the former increased the efficacy of the latter in some experiments ${ }^{45,46)}$. Neither theory has been proven clinically.

Schacter et al. ${ }^{41)}$ presents in vitro results which showed antagonistic effects of the coadministration.

Although AMPH inhibited C. albicans at $0.375 \mu \mathrm{g} / \mathrm{m} l$ when used alone, the MIC value almost doubled when MCZ was co-administered. This report is often cited as data which supports the presence of antagonism.

Graybill et al. ${ }^{44)}$ shows the results of an in vitro study on the effects of combination of AMPH and MCZ on Cryptococcus neoformans which did not support the presence of antagonism.

There were no significant differences between the MCZ group and the MCZ $(0.5 \mu \mathrm{g} /$ $\mathrm{m} l)+\mathrm{AMPH}(0.1 \mu \mathrm{g} / \mathrm{m} l)$ group, while the amount of fungi decreased marked in the MCZ $(0.5 \mu \mathrm{g} / \mathrm{ml})+\mathrm{AMPH}(0.1 \mu \mathrm{g} / \mathrm{ml})$ group compared to the AMPH group. This finding suggests that at least, there is no antagonistic effect.

Furthermore they showed no antagonism by the experiments in mice. Mice were observed for 60 days after infection with Cryptococcus neoformans in order to determine the survival 
rate. A high survival rate similar to that obtained in the AMPH group was obtained in the AMPH + MCZ group. This finding suggests that co-administration of the two drugs does not result in antagonism.

A number of studies have been conducted with respect to synergism of other antifungal agents. According to Polak ${ }^{47}$, the combinations of $\mathrm{AMPH}+$ flucytosine $(5 \mathrm{FC})$ and $5 \mathrm{FC}+$ itraconazole (ITZ) resulted in synergism or addictive effects on various Candida strains; the combination of $5 \mathrm{FC}+$ fluconazole (FCZ) resulted in synergism on some strains but not on others; AMPH and ITZ did not interact with each other or show antagonism. Against Cryptococcus spp., the combination of AMPH and $5 \mathrm{FC}$ resulted addictive effects, while $5 \mathrm{FC}$ and ITZ or $5 \mathrm{FC}$ and FCZ did not interact with each other. Against Aspergillus spp., the combination of $\mathrm{AMPH}$ and $5 \mathrm{FC}$ resulted addictive effects, while that of $5 \mathrm{FC}$ and ITZ resulted in synergism or addictive effects ; $5 \mathrm{FC}$ and FCZ did not interact; the combination of AMPH and ITZ resulted addictive effects or in antagonism.

In the meeting held a short while ago at Oiso, it was reported by Polak ${ }^{3)}$ that the combination of $5 \mathrm{FC}$ and AMPH resulted in marked synergism on Cryptococcus spp. and Candida spp. in vitro and in animals experiments; that the combination of $5 \mathrm{FC}$ and ITZ, FCZ or SM8668 resulted in significant synergism in animal models; and that the combination of $5 \mathrm{FC}$ and ITZ and that of $5 \mathrm{FC}$, FCZ and AMPH were more effective than the treatment with each drug alone and resulted in significant shortening of the treatment period in AIDS patients associated with cryptococcus infection.

\section{Interactions between azole derivatives and other drugs}

Caution is required with respect to drug interactions between antifungal agents, in particular azole derivatives and other drugs $5-9,48)$. (Table 4)

Since rifampicin accelerates the metabolism of antifungal agents and decreases their absorption, doses of antifungal agents need to be augmented when they are co-administered with rifampicin. In contrast, cyclosporin $\mathrm{A}$ delays the metabolism of antifungal agents and increases their blood concentrations,

Table 4. Drug interactions between azole antifungal agents and other medications

\begin{tabular}{l|c|c|c}
\hline \multirow{2}{*}{} & \multicolumn{2}{|c|}{ imidazole } & triazole \\
\cline { 2 - 4 } & MCZ & KCZ & FCZ \\
\hline cimetidine & $(-)$ & absorption $\uparrow$ & absorption $\downarrow$ \\
\hline rifampicin & absorption $\downarrow$ & enhance the metabolism \\
\hline cyclosporin A & plasma concentration $\uparrow$ & plasma concentration $\uparrow$ & plasma concentration $\uparrow$ \\
\hline phenytoin & plasma concentration $\uparrow$ & plasma concentration $\uparrow$ & plasma concentration $\uparrow$ \\
\hline antipyrine & $(-)$ & & plasma concentration $\uparrow$ \\
\hline warfarin & prothrombin time $\uparrow$ & prothrombin time $\uparrow$ & prothrombin time $\uparrow$ \\
\hline tolbutamide & blood sugar level $\downarrow$ & blood sugar level $\downarrow$ & blood sugar level $\downarrow$ \\
\hline $\begin{array}{l}\text { methyl predonisolone } \\
\text { sodium succinate }\end{array}$ & $(-)$ & maximum plasma $\uparrow$ & concentration \\
\hline alcohol & $(-)$ & disulfiram-like action & $(-)$ \\
\hline
\end{tabular}

MCZ: miconazole, KCZ: ketoconazole, FCZ: fluconazole 
increasing the risk of renal dysfunction ${ }^{49,50)}$. Cyclosporin A is often co-administered with anti-fungal agents in organ transplant patients. The dosage of cyclosporin A needs to be adjusted based on findings of the blood concentration monitoring. Kruger et al. ${ }^{51)}$ has reported that cyclosporin $\mathrm{A}$ and fluconazole do not have significant interaction with each other. The dose of cyclosporin A can be reduced when it is co-administered with ketoconazole since interactions are expected from the combination use.

Antifungal agents increase prothrombin time and bleeding tendency when they are co-administered with warfarin.

Close observation of patients is required when antifungal agents are co-administered with oral anti-diabetic drugs because the risk of hypoglycemia increases due to the delay in the metabolism of the latter.

\section{Conclusion}

Some findings from the literature and our own cases regarding various antifungal agents used for deep-seated mycosis with reference to recent progress in treatment and key points which must be taken into account in their clinical use were presented in this paper.

It was presented on the symposium "Recent Progress in Serodiagnosis and Chemotherapy for fungal diseases", at the 34 th Congress of Japanese Medical Mycology, at Oiso, Sept. 1990.

\section{Acknowledgements}

I thank Chairman Hideyo Yamaguchi for allowing me to make this presentation and Professors Yoshimura Fukazawa and Hideo Ikemoto for serving as moderators on this symposium.

\section{References}

1) Yamaguchi H: Development of antifungal agents -current status and future trend. $\mathrm{J}$ Clin Exper Med 154: 304-308, 1990.

2) Graybill $J$ R: New antifungal agents. Eur $J$ Clin Microbiol Infect Dis 8: 402-412,
1989.

3) Program and Abstracts of First International Conference on Antifungal Chemotherapy. (ICAFC' 90). Oiso, Japan. Sept. 1990.

4) Yamaguchi H, Uchida K, Orikasa $Y$, Matsumoto $\mathrm{T}$, Yamamoto $\mathrm{H}$, Inoue $\mathrm{S}$, Kondo $\mathrm{S}$ and Takeuchi T: Antifungal activity of Benanomycin A, a novel antibiotic. Abstract of 29th Interscience Con ference on antimicrobial agents and chemotherapy. (Houston, Texas.) No.715, 1989.

5) Ringel $\mathrm{S}$ M: New antifungal agents for the systemic mycoses. Mycopathol 109: 7587, 1990.

6) Fromtling $\mathrm{R} A$ : Overview of medically important antifungal azole derivatives. Clin microbiol Rev 1: 187-217, 1988.

7) Dismukes $\mathrm{W}$ E: Azole antifungal drugs: old and new. Ann Int Med 109: 177-179, 1988.

8) Saag M S and Dismukes W E: Azole antifungal agent: Emphasis on new triazoles. Antimicrob Agents and Chemother 32: 1-8, 1988.

9) Bailey E M, Krakovsky D J and Rybak $M$ J: The triazole antifungal agents: A review of itraconazole and fluconazole, Pharmacother 10: 146-153, 1990.

10) Cauwenbergh $G$, Legendre $R$ and Blatchford $\mathrm{N}$ : Itraconazole, a novel oral antifungal: Its efficacy and safety profile. Proceedings of VIII Congreso Bolivariano y XVII Congreso Colombiano de Dermatologia (Bogota, Colombia). p.12-22, 1988 Apr. 29May 3.

11) Denning $D W$, Tucker $R$ M, Hanson $L H$, Hamilton J R and Stevens D A: Itraconazole therapy for cryptococcal meningitis and cryptococcosis. Arch Int Med 149: 23012308, 1989.

12) DeBeule K, De Doncker P, Gauwenbergh G, Koster M, Legendre R, Blatchford N, Daunas J and Chwetzoff E: The treatment of aspergillosis and aspergilloma with itraconazole, Clinical results of an open international study (1982-1987). Mycoses 31: 476-485, 1988.

13) Denning $D$ W, Tucker $R$ M, Hanson $L H$ and Stevens D A: Treatment of invasive 
aspergillosis with itraconazole. Am J Med 86: 791-800, 1989.

14) Viviani M A, Tortorano A M, Longer $M$, Almaviva M, Negric, Cristina S, Scoccia S, DeMaria R, Fiocchi R, Ferrazzi P, Goglio A, Gavazzeni G, Faggian G, Rinaldi R and Cadrobbi P: Experience with itracon azole in cryptococcosis and aspergillosis. J Infect 18: 151-165, 1989.

15) Odds F C: Antifungal activity of saperconazole ( $\mathrm{R}$ 66905) in vitro. J Antimicrob Chemother 24: 533-537, 1989.

16) Mallie M, Montes B, Lebecq J C and Bastide $\mathrm{J} \mathrm{M}$ : In vitro antifungal activity of saperconazole (R66905) against Candida and Torulopsis. Mycosis 32: 631-637, 1989.

17) Custem J V, Gerven F V and Janssen $P$ A: Oral and parenteral therapy with saperconazole (R66905) of invasive aspergillosis in normal and immunocompromised animals. Antimicrob Agents and Chemother 33: 2063-2068, 1989.

18) Fromtling $\mathrm{R}$ A: SCH-39304. Drug of the future 14: 1165-1168, 1989.

19) Mclntyre $\mathrm{K} \mathrm{A}$ and Galgiani $\mathrm{J} \mathrm{N}$ : In vitro susceptibilities of yeasts to a new antifungal triazole, SCH 39304: Effects of test conditions and relation to in vivo efficacy. Antimicrob Agents and Chemother 33 : 1095-1100, 1989.

20) Meunier F, Lambert C and Van der Auwera P: In-vitro activity of $\mathrm{SCH} 39304$ in comparison with amphotericin B and fluconazole. J Antimicrob Chemother 25: 227-236, 1990.

21) Tanio $T$, Ichise $K$, Nakajima $T$ and Okuda $\mathrm{T}$ : In vivo efficacy of SM-8668 (Sch 39304), a new oral triazole antifungal agent. Antimicrob Agents and Chemother 34: 980-984, 1990.

22) Galgiani J N: Fluconazole, a new antifungal agent. Ann Int Med 113: 177-179, 1990.

23) Formulary Review. Diflucan ${ }^{\circledR}$ (fluconazole). USA, 1990.

24) Formulary information. Diflucan (8luconazole). USA, 1990.

25) Prescribing information. Diflucan (2) (fluconazole). USA, 1990.

26) Package insert "Ancotil Rosche" USA, 1990.
27) Janoff A, Boni L T, Popescu M C, Minchey $S R$, Cullis $P R$, Madden $T D$, Taraschi T, Gruner S M, Shyamsunder E, Tate M W, Mendelsohn $\mathrm{R}$ and Bonner D: Unusual lipid structures selectively reduce the toxity of amphotericin B. Proc Natl Acad Sci USA 85: 6122-6126, 1988.

28) Whitney R R, Kunselman L, Clark J M and Bonner D P: Efficacy of amphotericin B lipid complex (ABLC) in cryptococcal meningitis in normal or immunocomprised mice. Abstract of XXIX Interscience Conference on antimicrobial agents and Chemotherapy. (Houston, Texas) No. 166, 1989. Sept.

29) Miyazaki T, Kohno S, Yasuoka A, Maesaki S, Yamada H, Sasayama K, Dohtsu Y, Yamaguchi K, Hirota M, Hara K, Iwamoto $\mathrm{K}$, Murahashi $\mathrm{N}$ and Watanabe $\mathrm{T}$ : A lipid emulsion formulation of amphotericin $\mathrm{B}$ for the treatment of murine candidiasis and cryptococcosis. Chemother 38: 549-551, 1990.

30) Sano M, Akimoto Y, Sakashita A, Nakamaki T, Hino K, Suzuki K, Tomoyasu S and Tsuruoka N: Slow intravenous infusion therapy with amphotericin B for fungal infections complicated with acute leukemia. Antibiot and Chemother 5: 125132, 1989.

31) Takeshita A, Ohbayashi H, Endo $Y$ and Ikeda Y: Studies on proplylaxis withamphotericin B in acute leukemia receiving anticancer treatment. Program and abstract of 38th Jap. Congress on Chemotherapy. (Nagasaki). p.148, 1990.

32) Motomura S, Noguchi T, Kanamori $H$, Murata $\mathrm{T}$, Harano $\mathrm{H}$, Takahashi $\mathrm{K}$, Matsuzaki M, Miyashita H, Ogawa K, Ito A, Okubo $\mathrm{T}$ and Kodama F: The effect of oral highdose amphotericin B in the patients with acute leukemia: Detection of fungi and prophylaxis for fungal infection. Clin Hemat 28: 1956-1962, 1987.

33) Ito A: Not for publication.

34) Ikemoto $H$, Watanabe $K$, Mori $T$, Konno K, Oizumi K, Fukushima K, Ito A, Soejima R, Niki Y, Tsubura E, Tamura M, Hara $\mathrm{K}$ and Suzuyama Y: Clinical Study of miconazole on deep-seated fungal infections. Jpn J Antibiot 37: 615-662, 1984. 
35) Ikemoto $\mathrm{H}$, Watanabe $\mathrm{K}$, Mori $\mathrm{T}$, Taniuchi A, Akahonai Y, Mikuni C, Yoshida K, Kasai M, Kawamura K, Yoshida T, Konno K, Oizumi K, Aonuma S, Hayashi I, Ito A, Shimada K, Oka S, Nakata H, Miyahara $\mathrm{T}$, Shimada $J$ and other 58 authors:Clinical study of fluconazole on deep seated fungal infections. Jpn J Antibiot 42: 63-116, 1989.

36) Stern J J, Hartman B J, Sharkey P, Rowland V, Squires K E, Murray $\mathrm{H} W$ and Graybill R: Oral fluconazole therapy for patients with acquired immunodeficiency syndrome and cryptococcosis: Experience with 22 patients. Am J Med 85: 477-480, 1988.

37) Utz J P, Garriques I L, Sande M A, Warner J F, Mandell G L, McGehee R F, Duma $R J$ and Shadomy S: Therapy of cryptococcosis with a combination of flucytosine and amphotericin B. J Infect Dis 132: 368-373, 1975.

38) Jimbo $\mathrm{T}$, Tejima $\mathrm{Y}$ and Ikemoto $\mathrm{H}$ : Comparison among 5 -fluorocytosine, amphotericin $\mathrm{B}$ and combination of these two in therapeutic effectiveness for cryptococcal meningitis. Jpn J Med Mycol 18: 125-135, 1977.

39) Jimbo $\mathrm{T}$, Tejima $\mathrm{Y}$ and Ikemoto $\mathrm{H}$ : Comparison between 5 -fluorocytosine, amphotericin B and the combined administration of these agents in the therapeutic effectiveness for cryptococcal meningitis. Chemother 24: 374-389, 1978.

40) Benett J E, Dismukes $\mathrm{W} E$ and Duma R $\mathrm{J}$ : A comparison of amphotericin $\mathrm{B}$ alone and combined with flucytosine in the treatment of cryptococcal meningitis. New Eng J Med 301: 126-131, 1979.

41) Schacter L P, Owellen R J, Rathbun $H$ $\mathrm{K}$ and Buchanan B: Antagonism between miconazole and amphotericin B. Lancet Aug 7: 318, 1979.
42) Cosgrove R F, Beezer A E and Miles R $\mathrm{J}$ : In vitro studies of amphotericin $\mathrm{B}$ in combination with the imidazole antifungal compounds clotrimazole and miconazole. J Infect Dis 138: 681-685, 1978.

43) Dupont B and Drouhet E: In vitro synergy and antagonism of antifungal agents aga inst yeast-like fungi. Postgrad Med J 55: 683-686, 1979.

44) Graybill J R, Mitchell L and Levine H B: Treatment of experimental murine cryptococcosis: a comparison of miconazole and amphotericin B. Antimicrob Agents and Chemother 13: 277-283, 1978.

45) Odds F C: Interactions among amphotericin B, 5-fluorocytosine, ketoconazole, a nd miconazole against pathogenic fungi. Antimicrob Agents and Chemother 22: 763770, 1982.

46) Brajtburg J, Kobayashi D, Medoff G and Kobayashi G S: Antifungal action of amphotericin $\mathrm{B}$ in combination with other polyene on imidazole antibiotics. J Infect Dis 146: 138-146, 1982.

47) Polak A: Combination therapy of experimental candidiasis, cryptococcosis, aspergillosis and wangiellosis in mice. Chemother 33: 381-395, 1987.

48) Lazar J D and Witner K D: Drug interaction with fluconazole. Rev Infect Dis $\mathbf{1 2}$ (suppl 3): 327-333, 1990.

49) LA Delfa I, Xia $Y$ and Blaschke T F : Dose-dependent inhibition of cyclosporin metabolism in mice by fluconazole. Can J Physiol Pharmacol 68: 89-93, 1990.

50) Collignon $P$ and Hurley $B$ : Interaction between fluconazole and cyclosporin. Lancet Oct 7: 867-868, 1989.

51) Kruger H U, Schuler U, Zimmermann $R$ and Ehninger G: Absence of significant interaction of fluconazole with cyclosporin. J Antimicrob Chemother 24: 781-786, 1989. 